\title{
Bufalin induces apoptosis in human esophageal carcinoma ECA109 cells by inhibiting the activation of the $\mathrm{mTOR} / \mathrm{p} 70 \mathrm{~S} 6 \mathrm{~K}$ pathway
}

\author{
YAN DING $^{1}$, WEI LIU ${ }^{2}$, XIAOLING WANG ${ }^{1}$, LINGLING ZHANG ${ }^{1}$, \\ MENG ZHAO ${ }^{1}$, HUIYAN DENG ${ }^{1}$ and YUEPING LIU ${ }^{1}$ \\ ${ }^{1}$ Department of Pathology, The Fourth Hospital of Hebei Medical University; \\ ${ }^{2}$ Department of Surgery, The Third Hospital of Shijiazhuang, Shijiazhuang, Hebei 050011, P.R. China
}

Received April 26, 2016; Accepted March 7, 2018

DOI: $10.3892 / \mathrm{ol} .2018 .8526$

\begin{abstract}
The present study examined whether bufalin could induce human esophageal carcinoma ECA109 cells apoptosis via inhibiting the activation of mechanistic target of rapamycin $(\mathrm{mTOR}) / \mathrm{p} 70$ S6 kinase (p70S6K) pathway is discussed in this article. The present study used the esophageal squamous cell carcinoma ECA109 cell line to assess the apoptosis-inducing effects of bufalin via inhibition of the mTOR/p70S6K pathways. A plasmid containing the wild-type mTOR gene (wtmTOR) was transfected into ECA109 cells. The levels of p70S6K, phosphorylated (p)-p70S6K, cellular inhibitor of apoptosis-1 (cIAP-1) and Bcl-2-associated death promoter (BAD) in ECA109 cells were examined by western blot analysis, and apoptosis was detected by flow cytometry analysis and Giemsa staining. The results revealed that the expression of p-p70S6K was increased as the time progressed (at 0,12 and $24 \mathrm{~h}$ ), and then decreased at 30, 36, 42 and $48 \mathrm{~h}$ after transfection. The expression of cIAP-1 was significantly decreased as time progressed following the addition of bufalin, whereas that of BAD was increased. The levels of p-p70S6K and cIAP-1 were significantly higher in the wtmTOR-transfected group than in the control and empty vector-transfected groups, and then reduced following addition of bufalin; however, BAD expression was significantly lower in the wtmTOR-transfected group. The results of flow cytometry revealed the cell cycle of ECA109 was arrested at $\mathrm{G}_{2} / \mathrm{M}$ phase and the apoptotic rate was significantly lower in the wtmTOR-transfected group than in the control and empty vector-transfected groups, and then increased following addition of bufalin. In conclusion, the findings of the present study demonstrated that bufalin
\end{abstract}

Correspondence to: Dr Yueping Liu, Department of Pathology, The Fourth Hospital of Hebei Medical University, 12 Jiankang Road, Shijiazhuang, Hebei 050011, P.R. China

E-mail: annama@163.com

Key words: esophageal carcinoma, bufalin, apoptosis, mechanistic target of rapamycin/p70 S6 kinase, ECA109 cells induced apoptosis in esophageal carcinoma cells via the inhibition of the mTOR/p70S6K pathway and indicated that treatment with bufalin could be combined with chemotherapy to overcome the resistance of esophageal carcinoma cells to chemotherapeutic-induced apoptosis.

\section{Introduction}

Esophageal carcinoma, which including squamous cell carcinoma (SCC) and adenocarcinoma, is a common serious malignancy worldwide; it ranks eighth in incidence and fourth in mortality of all cancer types owing to its extremely aggressive nature and the poor survival rate of patients (1-3). The genesis of esophageal carcinoma is a gradual process that combining variety of carcinogenic factors and multiple stages, which includes various physical and chemical factors, the abnormal activation of signaling pathways, disequilibrium of apoptosis regulation and anti-apoptotic signaling. All of these changes result in the loss of normal regulatory mechanisms of cells, culminating in over-proliferation, which leads to the occurrence of cancer (4).

Bufalin is a cardiotonic steroid and a component of the traditional Chinese medicine, Chansu, which is obtained from the skin and parotid venom gland of toads (5). Owing to the similarity in the chemical structure between bufalin and digoxin, bufalin is expected to have a digoxin-like function $(5,6)$. Bufalin has been shown to induce apoptosis in leukemia and solid tumor cells (5-10). In recent years, studies have revealed that bufalin could effectively inhibit the proliferation of tumor cells, and also assessed its possible molecular mechanism (6-8). The results of previous research also demonstrated that bufalin could inhibit the activation of ERK pathway, accordingly inhibit the proliferation and migration of esophageal carcinoma cells (11); however, the mechanism of inducing apoptosis has remained unclear.

Data has revealed that the RAC serine/threonine-protein kinase (Akt)/mechanistic target of rapamycin (mTOR)/p70 S6 kinase (p70S6K) pathway broadly exists in every cell of organism $(12,13)$. This pathway is often irregularly activated in the genesis and development of tumor (12-14). Aberration of upstream signaling causes the phosphorylation of p70S6K, 
inhibits apoptosis, increases cell proliferation, produces abnormal translation of protein and induces tumor formation. Inhibition of mTOR can prevent the phosphorylation of p70S6K, inhibit the translation of protein, prevent cell cycle progression and induce cell apoptosis (15). On the basis of previous studies (15), the present study transfected human esophageal carcinoma ECA109 cells with wild-type mTOR (wtmTOR) and the changes to p70S6K, phosphorylated (p)-p70S6K, $\mathrm{Bcl}$-2-associated death promoter (BAD) and cellular inhibitor of apoptosis-1 (cIAP-1) protein were detected. The present study investigated the biochemical mechanisms of apoptosis by bufalin in human esophageal carcinoma cells. The current study assessed the influence of bufalin on ECA109 cell apoptosis, and attempted to reveal the function of gene intervention on development of tumor, and provide novel guidance for the clinical treatment of esophageal carcinoma.

\section{Materials and methods}

Cell lines. The human ESCC ECA109 cell line was purchased from Academia Sinica (Shanghai, China). All cells were cultured in Roswell Park Memorial Institute (RPMI)-1640 (Sijiqing, Beijing, China) enriched medium containing 1\% penicillin/streptomycin and 10\% fetal bovine serum (FBS; Sijiqing, Beijing, China). Cell culture plates were maintained in humidified incubators at $37^{\circ} \mathrm{C}$ in a $5 \% \mathrm{CO}_{2}$ incubator.

Reagents and antibodies. Bufalin was purchased from Sigma-Aldrich; Merck KGaA (Darmstadt, Germany) and was dissolved in ethyl alcohol to make a $0.01 \mathrm{~mol} / 1$ stock solution, which was kept at $-20^{\circ} \mathrm{C}$ and diluted in phosphate buffer saline (PBS) when used. A plasmid containing wtmTOR was produced by Prof. Hao Jun (Department of Pathology, Hebei Medical University). Rabbit anti-human polychonal antibodies p70S6K, phosphorylated (p)-p70S6K, cIAP-1, BAD and $\beta$-actin were purchased from Epitomics; Abcam (Cambridge, UK). The reagents of propidium iodide (PI) and RNAse for flow cytometry analysis were purchased from Sigma-Aldrich; Merck KGaA.

Transfection experiments. The transfection of wtmTOR plasmid $(3 \mu \mathrm{g})$ and empty vector $(3 \mu \mathrm{g})$ into ECA109 cells was performed using Lipofectamine 2000 (Life Technologies; Thermo Fisher Scientific, Inc., Waltham, MA, USA) and incubated for $24 \mathrm{~h}$. The wtmTOR plasmid was kindly provided by Professor Haojun (Department of Pathology, Hebei Medical University, Shijiazhuang, China). The empty vector (pEGFP-C1) was purchased from Invitrogen: Thermo Fisher Scientific, Inc. The cells were divided into four groups: The control group (untransfected group), the empty vector-transfected group, the wtmTOR transfected group, and the group treated with add bufalin $(60 \mathrm{nmol} / \mathrm{l})$ after $24 \mathrm{~h}$ transfection.

Protein extraction and western blot analysis. Cells were harvested and lysed with lysis buffer $(20 \mathrm{mM}$ sucrose, $1 \mathrm{mM}$ EDTA, $20 \mu \mathrm{M}$ Tris-Cl, pH 7.2, 1 mM DTT, $10 \mathrm{mM} \mathrm{KCl,} 1.5 \mathrm{mM}$ $\mathrm{MgCl}_{2}$ and $5 \mu \mathrm{g} / \mathrm{ml}$ aprotinin) for $30 \mathrm{~min}$. Protein concentration was measured using a Bio-Rad protein assay (Bio-Rad Laboratories, Inc., Hercules, CA, USA) according to the manufacturer's instructions. The total proteins ( $80 \mu \mathrm{g} / \mathrm{lane})$ were separated on $10 \%$ SDS-PAGEgel and blotted onto a nitrocellulose membrane. The membrane was incubated with blocking buffer and then was incubated overnight with anti-p70S6K antibody (T2921; 1:5,000; Epitomics: Abcam anti-p-p70S6K antibody (ab2571; 1:2,000; Epitomics: Abcam), anti-cIAP-1 antibody (3302-1; 1:2,000; Epitomics: Abcam), anti-BAD antibody (1541-1; 1:2,000; Epitomics: Abcam) and $\beta$-actin antibody (ab8226; 1:500; Epitomics: Abcam) primary antibodies at $4^{\circ} \mathrm{C}$. The membranes were washed three times with PBST and incubated for $1 \mathrm{~h}$ with a horseradish peroxidase-conjugated secondary antibody (goat anti-rabbit IgG-HRP; SAB3700852; 1:5,000; Sigma-Aldrich; Merck KGaA, Darmstadt, Germany). Blots were then developed with Super signal West Femto Maximum Sensitivity substrate (Pierce; Thermo Fisher Scientific, Inc.) on a FujiFilm LAS-3000 detection system (Fujifilm Corporation, Tokyo, Japan).

Giemsa staining. ECA109 cells were treated with $60 \mathrm{nmol} / \mathrm{l}$ bufalin for $48 \mathrm{~h}$, and the cells were collected and put on the slides. The slides were then rinsed with sterile water and stained with freshly prepared Giemsa stain solution (Giemsa: phosphate=1:9; BDH Chemicals; Merck KGaA) for $5 \mathrm{~min}$ at room temperature. Following three washes in sterile water, the cells were examined for morphological changes using a light microscope at $\mathrm{x} 400$, magnification.

Flow cytometry analysis. ECA109 cells were collected for PI staining. Briefly, the cells were fixed in $70 \%$ ethyl alcohol at $4^{\circ} \mathrm{C}$ overnight, then washed with PBS and incubated with RNAse $(10 \mu \mathrm{g} / \mathrm{ml})$ at $37^{\circ} \mathrm{C}$ for $30 \mathrm{~min}$. Next the cells were incubated with PI (final concentration, $10 \mu \mathrm{g} / \mathrm{ml}$ ) for $30 \mathrm{~min}$ in the dark. After incubating at $4^{\circ} \mathrm{C}$ for $30 \mathrm{~min}$, flow cytometry was performed. MultiCycle AV software (Version 295, Beckman Coulter, Miami, FL, USA) was used to analyze the cell cycle and Expo32 ADC software (Version 1.2, Beckman Coulter, Miami, FL, USA) was used to analyze the apoptosis rate.

Statistical analysis. All data are presented as the mean \pm standard deviation. Significant differences among the groups were determined by one-way ANOVA followed by Newman-Keuls method of post-hoc comparison. All results presented were obtained from at least three independent experiments. The statistical analyses were performed using SPSS 13.0 (SPSS, Inc., Chicago, IL, USA). P<0.05 was considered to indicate a statistically significant difference.

\section{Results}

Transfection with wtmTOR plasmid influences the expression of p70S6K and p-p70S6K protein in ECA109 cells by western blot analysis. The wtmTOR plasmid was amplified successfully and transfected into esophageal carcinoma ECA109 cells. The expression of p70S6K and the activation of p70S6K at 0 , $12,24,30,36,42$ and $48 \mathrm{~h}$ were examined by western blot analysis. The expression of p70S6K was not significantly different at $0,12,24,30,36,42$ or $48 \mathrm{~h}(0.599 \pm 0.011,0.594 \pm 0.013$, $0.606 \pm 0.012,0.608 \pm 0.010,0.592 \pm 0.017,0.599 \pm 0.021$, $0.600 \pm 0.036$, respectively; P>0.05). Therefore, $\mathrm{p}-\mathrm{p} 70 \mathrm{~S} 6 \mathrm{~K}$ levels increased along with the time (at 0, 12 and $24 \mathrm{~h}$, levels 
were $0.389 \pm 0.013,0.411 \pm 0.019$ and $0.609 \pm 0.016$, respectively), and then decreased at 30,36, 42 and $48 \mathrm{~h}$ following transfection $(0.573 \pm 0.015,0.394 \pm 0.013,0.383 \pm 0.006$ and $0.262 \pm 0.018$, respectively; $\mathrm{P}<0.05)$. The expression of $\mathrm{p}-\mathrm{p} 70 \mathrm{~S} 6 \mathrm{~K}$ was the highest at $24 \mathrm{~h}$. The difference was statistically significant. We selected $24 \mathrm{~h}$ as the optimal transfection time (Fig. 1).

Examination of cIAP-1 and BAD expression by western blot analysis following bufalin treatment. To confirm that bufalin induced ECA109 cell apoptosis, western blot analysis was performed to assess the expression of cIAP-1 and BAD following incubation with $60 \mathrm{nmol} / \mathrm{l}$ bufalin. The result showed that the expression of cIAP-1 was gradually decreased as time progressed for $2,6,12,24,36$, and $48 \mathrm{~h}(0.542 \pm 0.003$, $0.517 \pm 0.007,0.455 \pm 0.002,0.414 \pm 0.004,0.369 \pm 0.026$, $0.218 \pm 0.015$, respectively; $\mathrm{P}<0.05$ ), whereas the expression of BAD was gradually increased following addition of bufalin for $2,6,12,24,36$, and $48 \mathrm{~h}(0.456 \pm 0.009,0.659 \pm 0.042$, $0.750 \pm 0.023,0.813 \pm 0.019,0.937 \pm 0.013$ and $1.047 \pm 0.013$, respectively; $\mathrm{P}<0.05$ ) (Fig. 2). The difference was statistically significant.

Detection of $p 70 S 6 K, p-p 70 S 6 K, c I A P-1$ and BAD levels by western blot in different groups. The experiment was divided into four groups: The control group, empty vector transfected group, wtmTOR transfected group, and the bufalin/wtmTOR transfected group. Western blot analysis revealed that the level of p70S6K was not significant different in the control,compared with empty vector-transfected, wtmTOR-transfected, and the bufalin/wtmTOR-transfected groups $(0.901 \pm 0.045$, $0.914 \pm 0.023,0.900 \pm 0.020,0.898 \pm 0.022$, respectively; $\mathrm{P}>0.05$ ) (Fig. 3A). However, p-p70S6K was significantly higher in wtmTOR-transfected group compared with the control and empty vector groups, and then reduced following addition of bufalin for $2 \mathrm{~h}(0.761 \pm 0.085,0.766 \pm 0.068,0.952 \pm 0.059$, $0.762 \pm 0.019$; P<0.05; Fig. 3A).

The level of cIAP-1 was significantly higher in wtmTOR-transfected group compared with in control group, empty vector group, and addition of bufalin for $24 \mathrm{~h}$ $(0.721 \pm 0.019,0.731 \pm 0.248,0.840 \pm 0.010$ and $0.742 \pm 0.021$, respectively; $\mathrm{P}<0.05)$. On the contrary, the expression of BAD was significantly lower in wtmTOR-transfected group than in the control and empty vector group, and then increased following addition of bufalin for $24 \mathrm{~h}(0.929 \pm 0.046$, $0.944 \pm 0.060,0.779 \pm 0.182$ and $1.029 \pm 0.049$, respectively; $\mathrm{P}<0.05$; Fig. 3B).

Morphological analysis of ECA109 cells by Giemsa staining. To confirm that bufalin induced the morphology of apoptosis in ECA109 cells, ECA109 cells was treated with $60 \mathrm{nmol} / \mathrm{l}$ bufalin for $48 \mathrm{~h}$ and then Giemsa staining was performed. The apoptotic morphology was evident in bufalin-treated cells under a microscope at $\mathrm{x} 400$ magnification, including cytoplasmic shrinkage, nuclear condensation and the formation of apoptotic bodies (Fig. 4). However, no apoptotic morphology was observed in the control-treated cells.

Changes to ECA109 cells apoptotic rate and cell cycle detected by flow cytometry. Flow cytometry results showed that the apoptotic rate was gradually increased following addition of

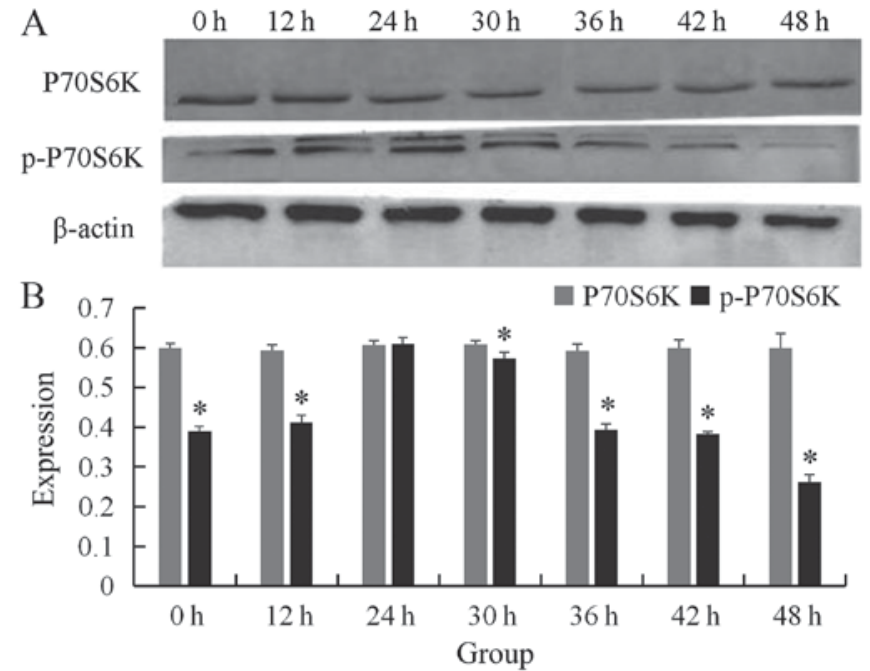

Figure 1. Transfecting wtmTOR plasmid influenced the expression of (A) p70S6K and p-p70S6K protein in ECA109 cells by western blot analysis. The expression of (B) p-p70S6K was increased along with the time $(0,12$, $24 \mathrm{~h}$ ), and then decreased at 30,36, 42 and $48 \mathrm{~h}$ following transfection. The expression of p-p70S6K was the highest at 24 h. ${ }^{*} \mathrm{P}<0.05$ vs. $24 \mathrm{~h}$. wtmTOR, wild-type mechanistic target of rapamycin; p-p70S6K, phosphorylated p70 S6 kinase.

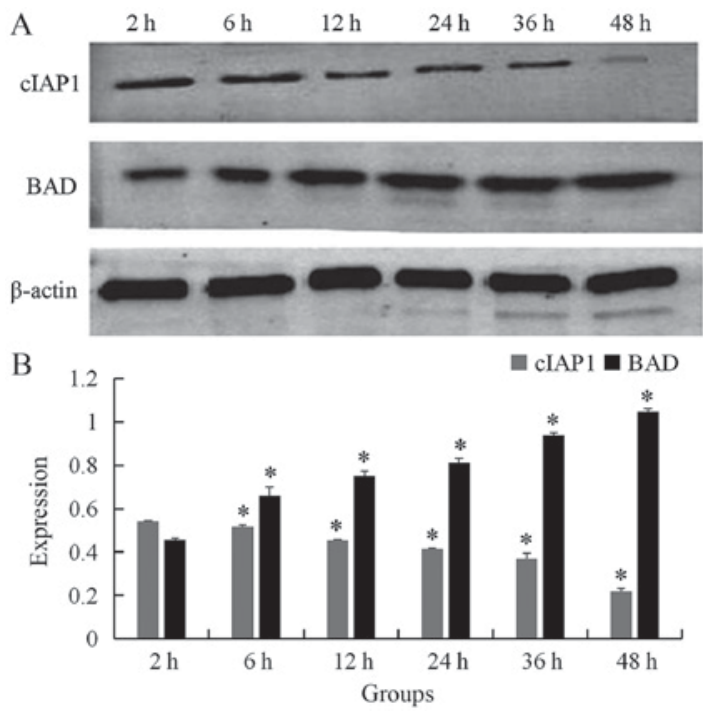

Figure 2. Expression of (A) cIAP-1 and BAD were examined by western blot analysis following addition of $60 \mathrm{nmol} / 1 \mathrm{bufalin}$. The expression of (B) cIAP-1 was gradually decreased along with the time, whereas the expression of BAD was gradually increased following addition of bufalin 2, 6 , $12,24,36$ and 48 h. ${ }^{*} \mathrm{P}<0.05$ vs. 2 h. cIAP-1, cellular inhibitor of apoptosis protein-1; BAD, Bcl-2-associated death promoter.

bufalin at concentrations of $0,20,40,60,80$ and $100 \mathrm{nmol} / \mathrm{l}$ for $24 \mathrm{~h}(3.01 \pm 0.317,3.67 \pm 0.306,6.74 \pm 0.198,7.59 \pm 0.340$, $18.22 \pm 0.651$ and $28.60 \pm 1.737 \%$, respectively; $\mathrm{P}<0.05$ ) (Fig. 5). The cell cycle of ECA109 was arrested at $\mathrm{G}_{2} / \mathrm{M}$ phase, and the cell percentage of $\mathrm{G}_{2} / \mathrm{M}$ is increased from $9.24 \pm 1.919$ to $70.5 \pm 2.934 \%$ following addition of bufalin from $0 \mathrm{nmol} / \mathrm{l}$ to $100 \mathrm{nmol} / \mathrm{l}$; this difference was statistically significant (Fig. 6).

The apoptotic rate of the cells in the different groups were examined, the results of which revealed that the apoptotic rate was significantly lower in wtmTOR-transfected group compared with in the control group, empty vector groups, and 

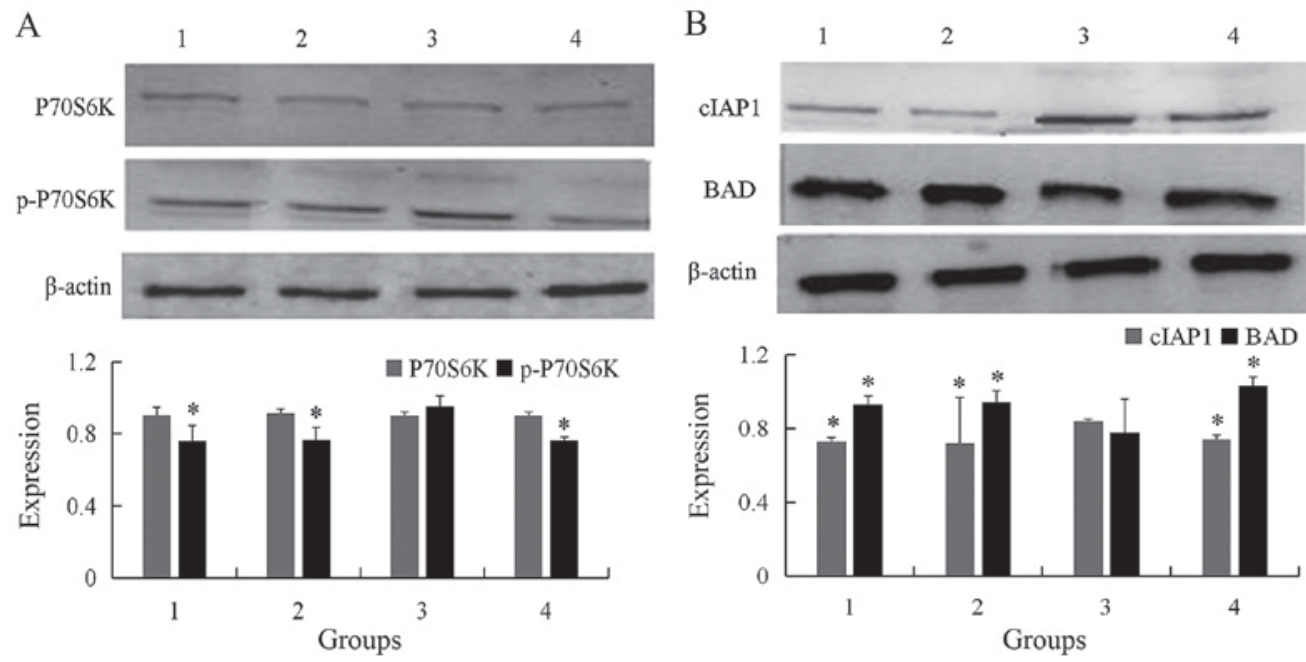

Figure 3. Western blot analysis of protein expression in the four different cell groups. (A) Expression of p70S6K and p-p70S6K in different groups were detected by western blot. The level of p-p70S6K was significantly higher in wtmTOR plasmid transfected group comparing with control and empty vector group, and then reduced following addition of bufalin $2 \mathrm{~h}$. (B) Expression cIAP-1 and BAD in different groups were detected by western blot analysis. The level of cIAP-1 was significantly higher in wtmTOR plasmid transfected group comparing with control and empty vector group, and then decreased following addition of bufalin for $24 \mathrm{~h}$. Contrarily, the expression of BAD was significantly lower in wtmTOR plasmid transfected group. "P $<0.05$ vs. wtmTOR-transfected group. Group 1, control; group 2, empty vector-transfected; group 3, wtmTOR-transfected; group 4, $60 \mathrm{nmol} / 1$ bufalin. p-p70S6K, phosphorylated p70 S6 kinase; wtmTOR, wild-type mechanistic target of rapamycin; BAD, Bcl-2-associated death promoter.

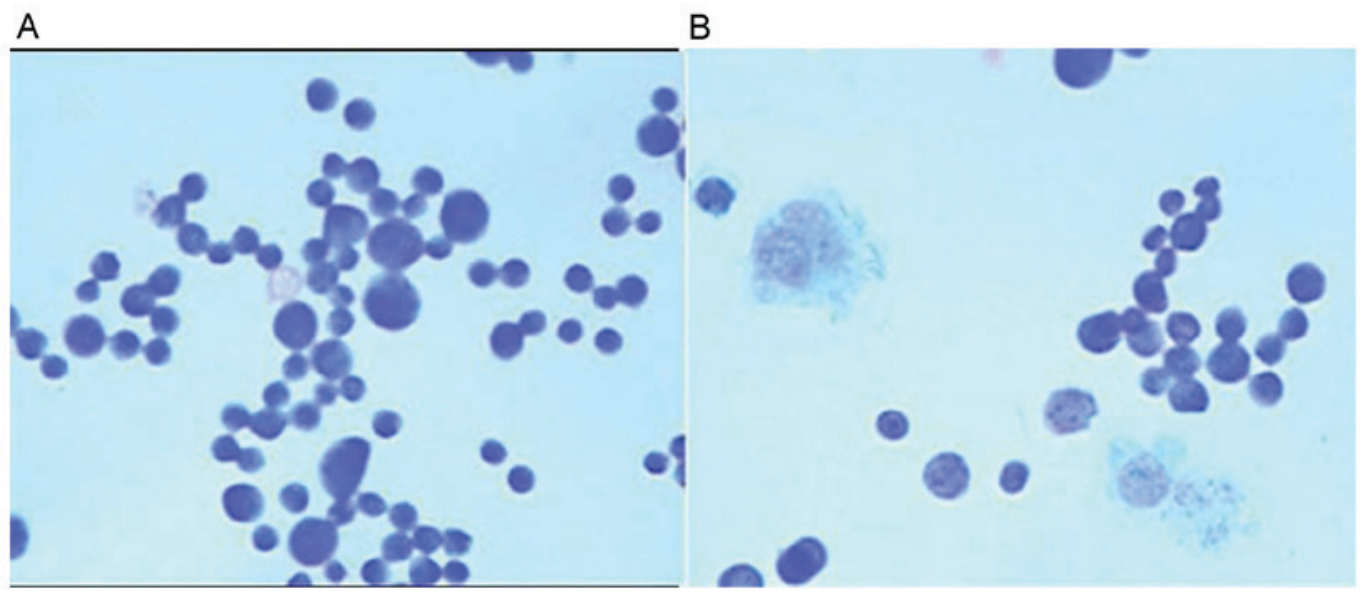

Figure 4. Apoptotic morphology of ECA109 cells treated with bufalin. ECA109 cells were treated with (A) vehicle or (B) $60 \mathrm{nmol} / \mathrm{l}$ bufalin for $48 \mathrm{~h}$ and stained with Giemsa. Cytoplasmic shrinkage, nuclear condensation and the formation of apoptotic bodies were observed in (B). Magnification, x400.

addition of bufalin for $24 \mathrm{~h}$ group $(5.60 \pm 0.411,5.46 \pm 0.341$, $4.19 \pm 0.210,10.12 \pm 0.325 \%$, respectively; all $\mathrm{P}<0.05$; Fig. 7).

\section{Discussion}

Esophageal carcinoma is a high-incidence malignancy in China, which also has a high morbidity and mortality rate in the rest of the world (16). The genesis and development of this disease is a complicated process, including the accumulation and interaction of several factors, phases and multiple gene variations. Patients are primarily treated with surgery combining with radiotherapy, chemotherapy or immunotherapy; however, the 5 -year survival rate remains low and the prognosis of patients is poor $(2,5)$. The genesis and development of tumor is closely associated with abnormities to signaling pathways $(14,17)$. The apoptosis signaling pathway activated by bufalin has attracted considerable attention (7-9); however, there is little research on esophageal carcinoma and the exact mechanism by which this pathway is activated is unclear.

Apoptosis is a cell defense mechanism to eliminate malignant cells and has a notable role in preventing tumor development. In fact, a number of anticancer drugs function primarily to induce apoptosis through regulating apoptosis-associated signaling $(18,19)$. Bufalin is a member of a class of toxic steroids purified from the traditional Chinese medicine Chansu. Previous studies have revealed that bufalin also exhibited antitumor effects; it induced the differentiation and apoptosis of leukemia HL-60 cells, and induce the apoptosis of gastric cancer cells, colon cancer cells and breast cancer cells (20-22). Bufalin could therefore induce cell cycle arrest and/or apoptosis as concentration increased. The cell cycle is divided into $G_{0} / G_{1}, S$, and $G_{2} / M$ phases, which refers to the presynthetic phase, synthesis period, and post-synthetic phase of DNA, respectively (23). The cell cycle is a useful 

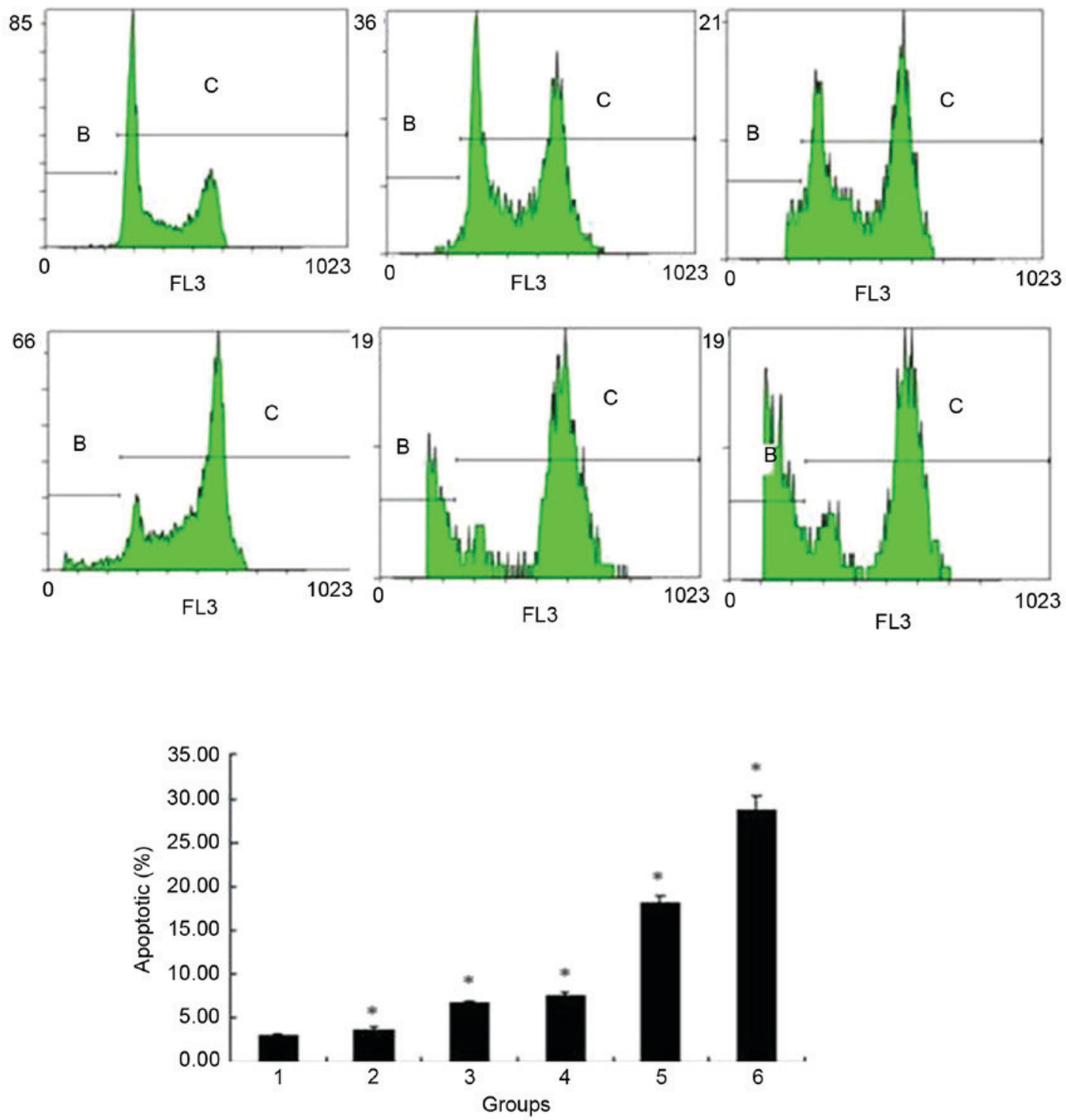

Figure 5. Flow cytometry analysis of the apoptotic rate of ECA109 cells treated with different concentrations of bufalin. The apoptotic rate gradually increased following addition of $0,20,40,60,80$ or $100 \mathrm{nmol} / 1$ bufalin for $24 \mathrm{~h}$. Group 1, $0 \mathrm{nmol} / 1$; group 2, $20 \mathrm{nmol} / 1$; group 3, $40 \mathrm{nmol} / 1$; group 4, $60 \mathrm{nmol} / 1$; group 5 , $80 \mathrm{nmol} / \mathrm{l}$; group $6,100 \mathrm{nmol} / \mathrm{l}$. "P<0.05 vs. control.

index for judging the status of cell proliferation. At present, there are several reports concerning bufalin-induced cell cycle retardation. A prior study revealed that bufalin mainly induced $\mathrm{G}_{2} / \mathrm{M}$ phase arrest in leukemia ML1 cells (24). Another study reported that bufalin could induce $\mathrm{G}_{0} / \mathrm{G}_{1}$ phase arrest in endometriosis matrix cell (25). Together, these results demonstrated that the influence of bufalin on cell cycle varied in different cells. However, the present study assessed whether bufalin could induce apoptosis in esophageal carcinoma cells and arrest the cell cycle. In the current study, flow cytometry analysis demonstrated that as bufalin concentration increased $(0,20$, $40,60,80,100 \mathrm{nmol} / \mathrm{l}$ ) the apoptotic rate of ECA109 increased from $3.01 \pm 0.317 \%$ (bufalin, $0 \mathrm{nmol} / \mathrm{l}$ ) to $28.60 \pm 1.737 \%$ (bufalin, $100 \mathrm{nmol} / \mathrm{l}$ ) at $24 \mathrm{~h}$ of treatment with bufalin. The percentage of cells in $\mathrm{G}_{2} / \mathrm{M}$ phase was $70.5 \pm 2.934 \%$ compared with that in control group, which was $9.24 \pm 1.919 \%$. The expression of cIAP-1 protein, which is a member of the IAP family, gradually decreased as the time of bufalin incubation increased effecting on esophageal carcinoma cells ECA109.
The expression of the apoptosis-promoting gene $\mathrm{BAD}$, which belongs to the Bcl-2 family, gradually increased as the time of incubation increased. These results revealed that bufalin might induce cell cycle arrest at $\mathrm{G}_{2} / \mathrm{M}$ phase, and affect apoptosis of ECA109 cells on in a time- and dose-dependent manner.

A variety of signaling pathways are abnormally activated in the development of tumor; one such pathway, the $\mathrm{PI} 3 \mathrm{~K} / \mathrm{Akt} / \mathrm{mTOR}$ pathway, has been demonstrated to serve an essential role in the genesis of esophageal carcinoma. The $\mathrm{PI} 3 \mathrm{~K} / \mathrm{Akt} / \mathrm{mTOR}$ pathway is a notable signal transduction pathway that mediates tumor cell apoptosis. Activation of this pathway could inhibit apoptosis, increase cell cycle progression, and accordingly improve the survival and proliferation of tumor cells $(12,15,26)$. mTOR contributes to the genesis and development of a variety of malignancies, including breast cancer (27) and lung cancer (28). mTOR accelerates the translation and expression of protein, alters the cell cycle distribution, affects apoptosis and participates in adjusting multiple types of physiological and pathological changes 


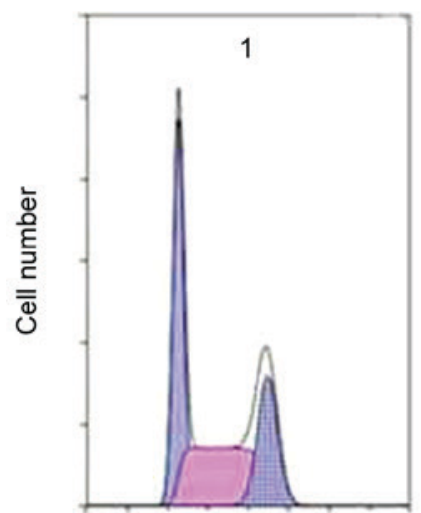

DNA content

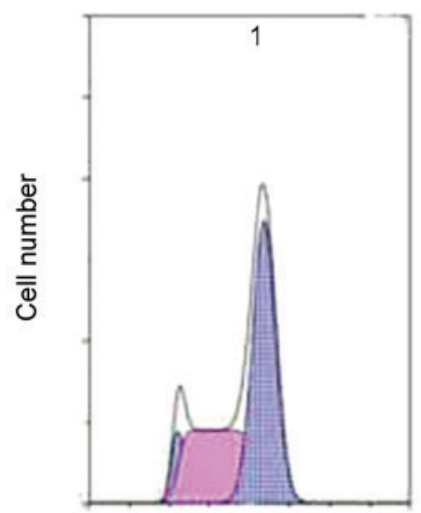

DNA content

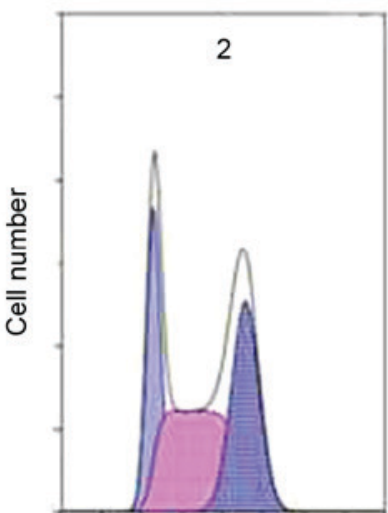

DNA content

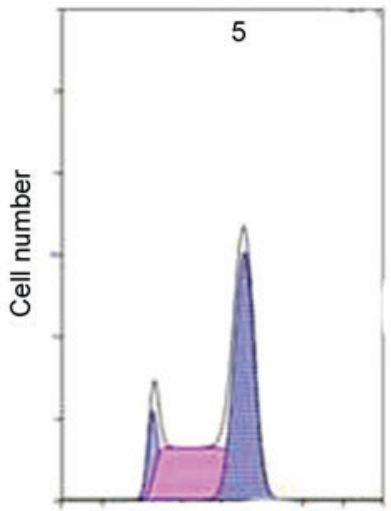

DNA content

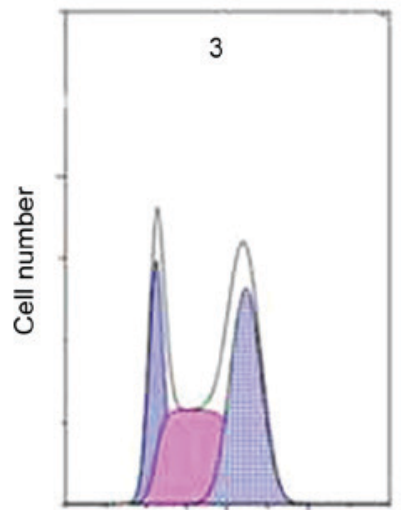

DNA content

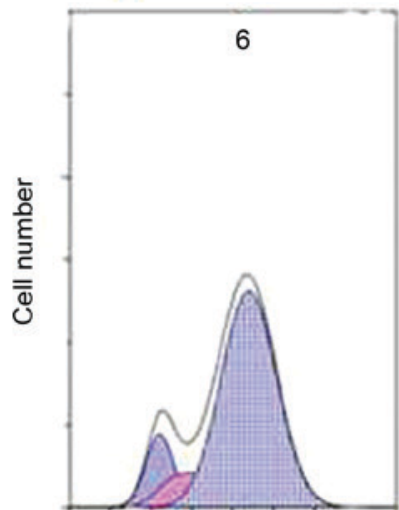

DNA content

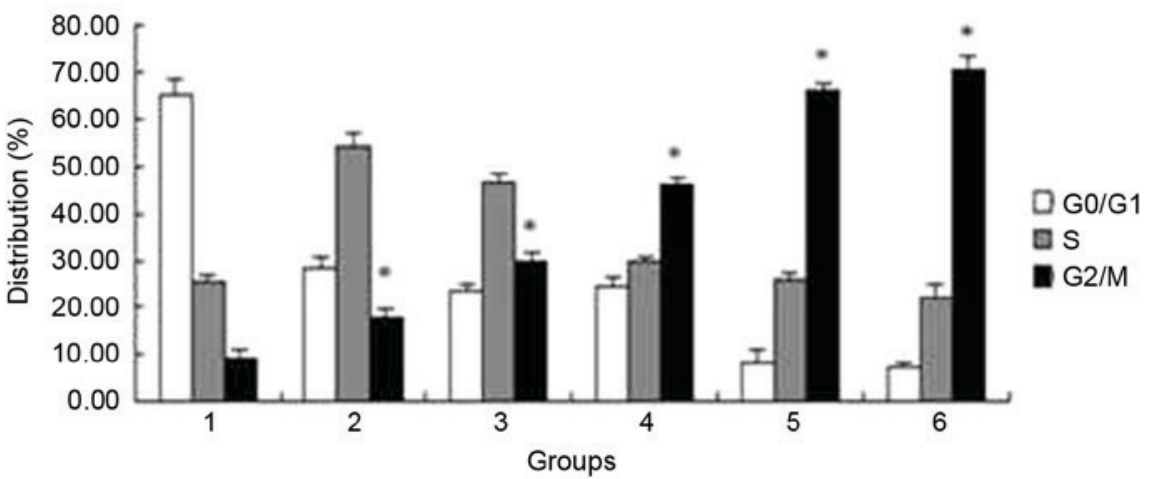

Figure 6. Flow cytometry analysis of cell cycle following the addition of different concentrations of bufalin. The cell cycle of ECA 109 was arrested at $\mathrm{G}_{2} / \mathrm{M}$ phase. Group 1, $0 \mathrm{nmol} / 1$; group 2, $20 \mathrm{nmol} / 1$; group 3, $40 \mathrm{nmol} / 1$; group 4, $60 \mathrm{nmol} / 1$; group 5, $80 \mathrm{nmol} / 1$; group 6, $100 \mathrm{nmol} / 1$. "P<0.05 vs. control.

in the organism, mainly through phosphorylating the main signal factors p70S6K and Eukaryotic translation initiation factor 4E-binding protein 1 (4E-BP1) downstream $(13,29)$. Activated mTOR can positively regulate the translation of S6K1, which phosphorylates p70S6 downstream, and promotes protein synthesis; this process promotes the synthesis of protein $(15,29)$. 4E-BP1 is another notable regulation pathway downstream of mTOR; it combines with the cap-binding protein in its dephosphorylated state, inhibiting the origin of translation. Activated mTOR can phosphorylate $4 \mathrm{E}-\mathrm{BP} 1$, and eukaryotic translation initiation factor $4 \mathrm{E}$ is released and form compound with other translation original factors, initiating translation and accelerating the expression of proteins associated with growth and differentiation (30). Therefore, the PI3K/Akt/mTOR pathway is considered to be an essential signaling pathway in protein synthesis that participates in the regulation of cellular proliferation, differentiation and apoptosis.

The present study successfully transfected the active mTOR plasmid wtmTOR into the ECA109 cell line. Previous studies revealed that the consisting activated mTOR signaling pathway could promote the transformation of normal cells to tumor cells $(9,31)$. If the tumor cells could be reverted to the non-transformation form in vitro following inhibition of the mTOR signal transduction pathway, this reversion could have a role in inhibiting tumor development. Accordingly, the present study used bufalin in different treatment groups and assessed the changes in activation of the mTOR signaling pathway and the apoptosis-associated proteins cIAP-1 and BAD. The levels of p-p70S6K level in the wtmTOR-transfected group increased as the transfection period increased, and reached the maximum value at $24 \mathrm{~h}$, and then gradually decreased; however, the 

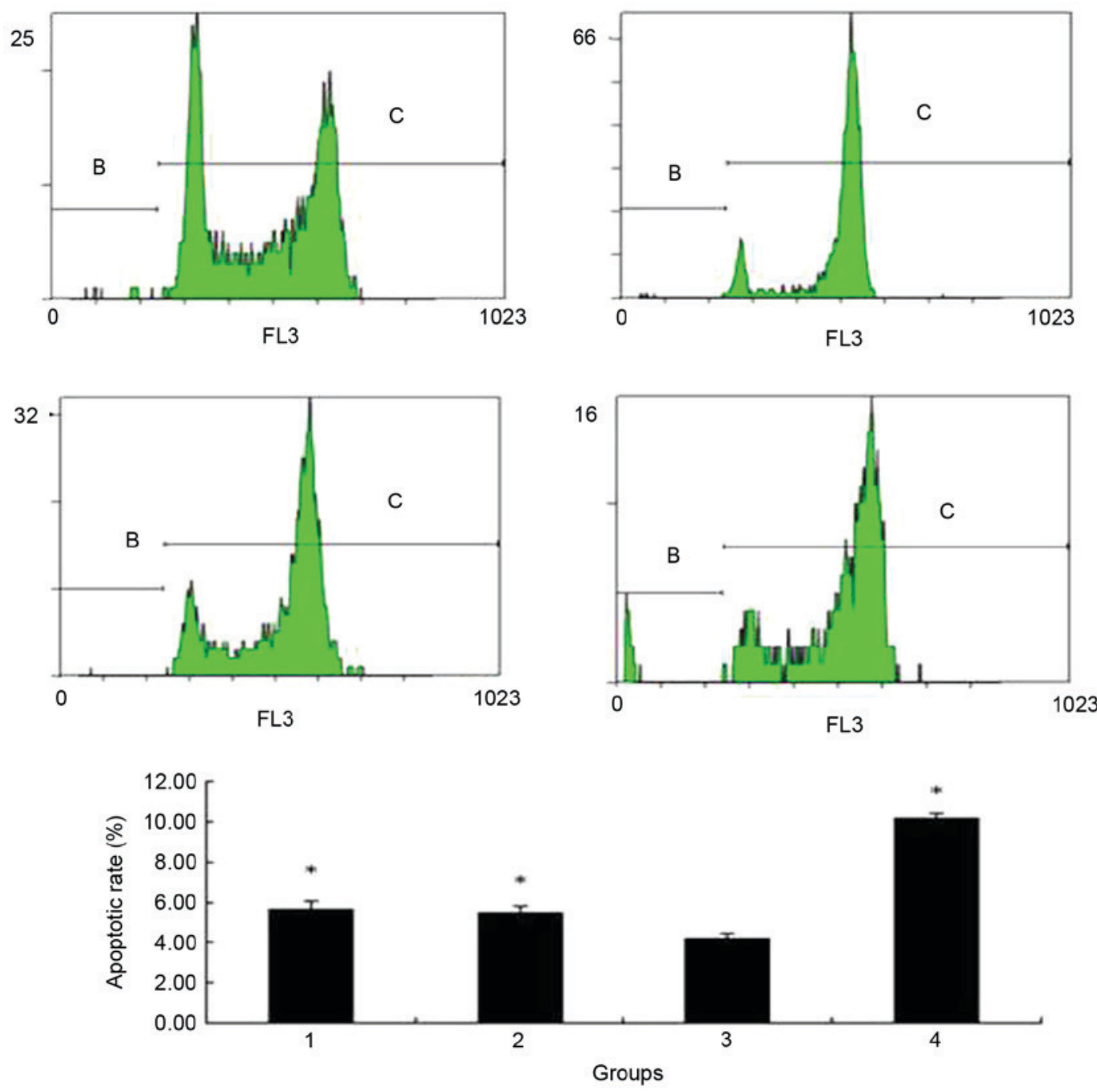

Figure 7. Flow cytometry analysis of the apoptotic rate of ECA109 cells in different groups. The apoptotic rate was significantly lower in the wtmTOR-transfected group than in the control and empty vector-transfected groups, but increased following addition of bufalin for $24 \mathrm{~h}$. Group 1, control; group 2, empty vector-transfected; group 3, wtmTOR-transfected; group 4, $60 \mathrm{nmol} / 1$ bufalin following wtmTOR transfection. ${ }^{*} \mathrm{P}<0.05$ vs. wtmTOR-transfected group. wtmTOR, wild-type mechanistic target of rapamycin.

expression of p70S6K did not evidently change. For different treatment groups, the level of p70S6K activated (that is, p-p70S6K) in wtmTOR-transfected group was evidently higher than in the control, empty vector-transfected and bufalin-treated group. The transfection of plasmid makes the activation of p70S6K increase, whereas bufalin could inhibit this process. The expression of cIAP-1 was higher in the wtmTOR-transfected group than the others, despite the lower expression of BAD than in the other three groups, which revealed that transfection with this plasmid inhibited cell apoptosis, whereas bufalin promotes cell apoptosis. The results of the present study indicated that bufalin could inhibit the development of esophageal carcinoma by inhibiting the mTOR pathway and inducing cell apoptosis.

In summary, the results of the present study indicate that bufalin induces cell apoptosis through inhibiting the activation of the mTOR/p70S6K signaling pathway. These results indicated that bufalin could be used for clinical treatment and provided an experimental basis and future direction for the treatment of esophageal carcinoma. Bufalin may represent a novel antitumor drug, meaning that its feasibility and clinical utility degree should be thoroughly investigated.

\section{Acknowledgements}

Not applicable.

\section{Funding}

The present study was supported by a grant from National Nature Science Foundation of P.R. China (grant no. 81303271).

\section{Availability of data and materials}

All data generated or analyzed during this study are included in this published article.

\section{Authors' contributions}

YD performed cell culture and was a major contributor in writing the manuscript. WL performed the flow cytometry analysis. XW was mainly responsible for the analysis of flow cytometry and revision of the paper. LZ performed western blotting experiments and analysis. MZ performed Giemsa 
staining. HD performed transfection experiments. YL was responsible for the analysis of data and the revision of the paper. All authors read and approved the final manuscript.

\section{Ethics approval and consent to publish}

Not applicable.

\section{Consent for publication}

Not applicable.

\section{Competing interests}

The authors declare that they have no competing interests.

\section{References}

1. Cai EH, Gao YX, Wei ZZ, Chen WY, Yu P and Li K: Serum miR-21 expression in human esophageal squamous cell carcinomas. Asian Pac J Cancer Prev 3: 1563-1567, 2012.

2. Mao WM, Zheng WH and Ling ZQ: Epidemiologic risk factors for esophageal cancer development. Asian Pac J Cancer Prev 12: 2461-2466, 2011.

3. Enziger PC and Mayer RJ: Esophageal cancer. N Engl J Med 349: 2241-2252, 2003.

4. Li B, Li J, Xu WW, Guan XY, Qin YR, Zhang LY, Law S, Tsao SW and Cheung AL: Suppression of esophageal tumor growth and chemoresistance by directly targeting the PI3K/AKT pathway. Oncotarget 5: 11576-11587, 2014.

5. Watabe M, Kawazoe N, Masuda Y, Nakajo S and Nakaya K: Bcl-2 protein inhibits bufalin-induced apoptosis through inhibition of mitogen-activated protein kinase activation in human leukemia U937 cells. Cancer Res 57: 3097-3100, 1997.

6. Yeh JY, Huang WJ, Kan SF and Wang PS: Effects of bufalin and cinobufagin on the proliferation of androgen dependent and independent prostate cancer cells. Prostate 54: 112-124, 2003.

7. Zhu Z, Li E, Liu Y, Gao Y, Sun H, Wang Y, Wang Z, Liu X, Wang Q and Liu Y: Bufalin induces the apoptosis of acute promyelocytic leukemia cells via the downregulation of survivin expression. Acta Heamatol 128: 144-150, 2012.

8. Zhu Z, Sun H, Ma G, Wang Z, Li E, Liu Y and Liu Y: Bufalin induces lung cancer cell apoptosis via the inhibition of PI3K/Akt pathway. Int J Mol Sci 13: 2025-2035, 2012.

9. Li D, Qu X, Hou K, Zhang Y, Dong Q, Teng Y, Zhang J and Liu Y: PI3K/Akt is involved in bufalin- induced apoptosis in gastric cancer cells. Anticancer Drugs 20: 59-64, 2009.

10. Hong $\mathrm{SH}$ and Choi YH: Bufalin induces apoptosis through activation of both the intrinsic and extrinsic pathways in human bladder cancer cells. Oncol Rep 27: 114-120, 2012.

11. Chen YN, Deng HY and Zhang P: Bufalin Inhibits the Proliferation of human esophageal carcinoma TE13 cells through down-regulation of ERK. Asian J Pharm Nurs Med Sci 2: 90-98, 2014.

12. Ponnurangam S, Standing D, Rangarajan P and Subramaniam D: Tandutinib inhibits the Akt/mTOR signaling pathway to inhibit colon cancer growth. Mol Cancer Ther 12: 598-609, 2013.

13. Meng Q, Xia C, Fang J, Rojanasakul Y and Jiang BH: Role of $\mathrm{PI} 3 \mathrm{~K}$ and AKT specific isoforms in ovarian cancer cell migration, invasion and proliferation through the p70S6K1 pathway. Cell Signal 18: 2262-2271, 2006.
14. Ji J and Zheng PS: Activation of mTOR signaling pathway contributes to survival of cervical cancer cells. Gynecol Oncol 117: 103-108, 2010.

15. Liu Y, Wang X, Jia Y and Liu Y: Effects of bufalin on the mTOR/p70S6K pathway and apoptosis in esophageal squamous cell carcinoma in nude mice. Int J Mol Med 40: 357-366, 2017.

16. Zhang Y: Epidemiology of esophageal cancer. World J Gastroenterol 14: 5598-5606, 2013

17. Engels K, Knauer S K, Metzler D, Simf C, Struschka O, Bier C, Mann W, Kovács AF and Stauber RH: Dynamic intracellular survivin in oral squamous cell carcinoma: Underlying molecular mechanism and potential as an early prognostic marker. J Pathol 211: 532-540, 2007.

18. Li W, Wang J, Jiang HR, Xu XL, Zhang J, Liu ML and Zhai LY: Combined effects of cyclooxygenase- 1 and cyclooxygenase- 2 selective inhibitors on ovarian carcinoma in vivo. Int $\mathrm{J}$ Mol Sci 12: 668-681, 2011.

19. Khoo BY, Chua SL and Balaram P: Apoptotic effects of chrysin in human cancer cell lines. Int J Mol Sci 11: 2188-2199, 2010.

20. Chen A, Yu J, Zhang L, Sun Y, Zhang Y, Guo H, Zhou Y, Mitchelson K and Cheng J: Microarray and biochemical analysis of bufalin-induced apoptosis of HL-60 cells. Biotechnol Lett 31: 487-494, 2009

21. Takai N, Ueda T, Nishida M, Nasu K and Narahara H: Bufalin induces growth inhibition, cell cycle arrest and apoptosis in human endometrial and ovarian cancer cells. Int J Mol Med 21: 637-643, 2008.

22. Xie CM, Chan WY, Yu S, Zhao J and Cheng CH: Bufalin induces autophagy-mediated cell death in human colon cancer cells through reactive oxygen species generation and JNK activation. Free Radic Biol Med 51: 1365-1375, 2011.

23. Ding L, Huang Y, Dai M, Zhao X, Du Q, Dong F, Wang L, Huo R, Zhang W, Xu X and Tong D: Transmissible gastroenteritis virus infection induces cell cycle arrest at $\mathrm{S}$ and $\mathrm{G} 2 / \mathrm{M}$ phases via p53-dependent pathway 178: 241-251, 2013.

24. Jing Y, Watabe M, Hashimoto S, Nakajo S and Nakaya K: Cell cycle arrest and protein kinase modulating effect of bufalin on human leukemia ML1 cells. Anticancer Res 14: 1193-11198, 1994.

25. Nasu K, Nishida M, Ueda T, Takai N, Bing S, Narahara H and Miyakawa I: Bufalin induces apoptosis and the G0/G1 cell cycle arrest of endometriotic stromal cells: A promising agent for the treatment of endometriosis. Mol Hum Reprod 11: 817-823, 2005.

26. Nishioka C, Ikezoe T, Yang J, Koeffler HP and Yokoyama A: Blockade of mTOR Signaling potentiates the ability of histone deacetylase inhibitor to induce growth arre stand differentiation of acute myelogenous leukemia cells. Leukemia 22: 2159-2168, 2008.

27. Lin HJ, Hsieh FC, Song H and Lin J: Elevated phosphorylation and activation of PDK-1/AKT pathway in human breast cancer. Br J Cancer 93: 1372-1381, 2005.

28. Tsurutani J, West KA, Sayyah J, Gills JJ and Dennis PA: Inhibition of the phosphatidylinositol 3-kinase/Akt/ mammalian target of rapamycin pathway but not the WTMTOR/ p70S6K pathway attenuates laminin-mediated small cell lung cancer cellular survival and resistance to imatinib mesylate or chemotherapy. Cancer Res 65: 8423-8432, 2005.

29. Fenton TR, Gwalter J, Cramer R and Gout IT: S6K1 is acetylated at lysine 516 in response to growth factor stimulation. Biochem Biophys Res Commun 398: 400-405, 2010.

30. Darb-Esfahani S, Faggad A, Noske A, Weichert W, Buckendahl AC, Müller B, Budczies J, Röske A, Dietel M and Denkert C: Phospho-mTOR and phospho-4EBP1 in endometrial adenocarcinoma: association with stage and grade in vivo and link with response to rapamycin treatment in vitro. Cancer Res Clin Oncol 135: 933-941, 2009.

31. Sutherland S: Several therapies may prevent or reduce the severity of oral mueositis associated with cancer treatment. Evid Based Dent 7: 104-105, 2006. 